\title{
Extended Regular Intuitionistic Fuzzy Graphs
}

\author{
V. Nivethana ${ }^{1}$, A. Parvathi ${ }^{2}$ \\ ${ }^{1}$ Department of Mathematics, Sri Venkateswara Institute of Science and Technology, Thiruvallur, India, \\ ${ }^{2}$ Dean and Professor, Department of Mathematics, Avinashilingam University, Coimbatore, India.
}

\begin{abstract}
In this paper, we introduce a new notion on degree of vertices and degree of edges in IFG and also introduce extended vertex regular IFG's and extended edge regular IFG's. The necessary conditions for extended regular IFG's are analyzed. An illustrative application in which extended vertex/edge regular IFG becomes a useful tool in the analysis of stemcell therapy and its effectiveness is also provided.
\end{abstract}

Mathematics Subject Classification: 05C72, 03E72, 03F55

Keywords: Extended degree of vertex, extended degree of edge and extended regular IFG.

\section{Introduction}

Atanassov[2] introduced the concept of Intuitionistic Fuzzy (IF) relations and intuitionistic fuzzy graphs (IFG). Later the study on intuitionistic fuzzy graphs found spontaneous growth as a branch of combinatorics, witnessing application areas in different disciplines including medical and life sciences, management sciences, social sciences, engineering, statistics, artificial intelligence, signal processing, pattern recognition, computer networking, decision making etc. Intuitionistic fuzzy graph model is a useful tool as it reduces the inconvenience of traditional numerical models used in engineering and other sciences and thus increases the use of symbolic models as in expert systems.

In [8], Parvathi and Karunambigai elaborated the study on IFG by explicitly defining operations on IFG. In [6] Nivethana and Parvathi A. analyzed those operations for vertex sets with one or more common vertices. In [9], authors Radha and Kumaravel introduced the concept of edge regular fuzzy graphs. In [3, 4], Karunambigai, Sivasankar and Palanivel studied regular IFG and their properties, which motivated us to introduce extended edge regular IFGs. In section 2, the preliminary definitions needed are discussed. In section 3, we introduce the definitions of extended edge degree, extended vertex regular IFG, extended edge regular IFG and extended regular IFG and then we study their properties. The necessary conditions for an IFG to be an extended edge regular IFG are also analyzed. In section 4, an application of extended edge/vertex regular IFG in stem cell therapy which generates a symbolic model (IFG) that makes the analysis of the effectiveness of the treatment more convenient and easier is provided.

\section{Preliminary and Definitions}

Definition: 2.1 An intuitionistic fuzzy graph (IFG) is of the form G: (V, E) where,

i. $\quad \mathrm{V}$ is finite non-empty set of vertices such that $\mu_{\mathrm{A}}: \mathrm{V} \rightarrow[0,1]$ and $v_{\mathrm{A}}: \mathrm{V} \rightarrow[0,1]$ denotes the degree of membership and non-membership of the elements $x \in V$ respectively and $0 \leq \mu_{\mathrm{A}}(\mathrm{x})+v_{\mathrm{A}}(\mathrm{x}) \leq 1$ for every $\mathrm{x} \in \mathrm{V}$.

ii. $\quad \mathrm{E} \subset \mathrm{V} \times \mathrm{V}$ is finite set of edges such that $\mu_{\mathrm{B}}: \mathrm{V} \times \mathrm{V} \rightarrow[0,1]$ and $\nu_{\mathrm{B}}: \mathrm{V} \times \mathrm{V} \rightarrow[0,1]$ are such that $\mu_{\mathrm{B}}(\mathrm{xy}) \leq \min \left\{\mu_{\mathrm{A}}(\mathrm{x})\right.$, $\left.\mu_{\mathrm{A}}(\mathrm{y})\right\}$ and $\nu_{\mathrm{B}}(\mathrm{xy}) \leq \max \left\{v_{\mathrm{A}}(\mathrm{x}), v_{\mathrm{A}}(\mathrm{y})\right\}$ and $0 \leq \mu_{\mathrm{B}}(\mathrm{xy})+\nu_{\mathrm{B}}(\mathrm{xy}) \leq 1$ for every $(\mathrm{x}, \mathrm{y}) \in \mathrm{E}$.

Definition: 2.2 The complement of an IFG, G: (V, E) is an IFG, $\bar{G}:(\bar{V}, \bar{E})$ where

$$
\begin{aligned}
& \text { i. } \overline{\mathrm{V}}=\mathrm{V} \\
& \text { ii. } \quad \bar{\mu}_{\mathrm{A}}(\mathrm{x})=\mu_{\mathrm{A}}(\mathrm{x}) ; \bar{v}_{\mathrm{A}}(\mathrm{x})=v_{\mathrm{A}}(\mathrm{x}) \quad \forall \mathrm{x} \in \mathrm{V} \\
& \text { iii. } \bar{\mu}_{\mathrm{B}}(\mathrm{xy})= \begin{cases}{\left[\mu_{\mathrm{A}}(\mathrm{x}) \wedge \mu_{\mathrm{A}}(\mathrm{y})\right]-\mu_{\mathrm{B}}(\mathrm{xy})} & \forall \mathrm{xy} \in \mathrm{E} \\
{\left[\mu_{\mathrm{A}}(\mathrm{x}) \wedge \mu_{\mathrm{A}}(\mathrm{y})\right]} & \forall \mathrm{xy} \notin \mathrm{E}\end{cases} \\
& \bar{v}_{\mathrm{B}}(\mathrm{xy})= \begin{cases}{\left[v_{\mathrm{A}}(\mathrm{x}) \vee v_{\mathrm{A}}(\mathrm{y})\right]-v_{\mathrm{B}}(\mathrm{xy})} & \forall \mathrm{xy} \in \mathrm{E} \\
{\left[v_{\mathrm{A}}(\mathrm{x}) \vee v_{\mathrm{A}}(\mathrm{y})\right]} & \forall \mathrm{xy} \notin \mathrm{E}\end{cases}
\end{aligned}
$$

Definition: 2.3 An IFG G:(V, E) is said to be strong IFG if $\mu_{\mathrm{B}}(\mathrm{xy})=\mu_{\mathrm{A}}(\mathrm{x}) \wedge \mu_{\mathrm{A}}(\mathrm{y})$ and $\nu_{\mathrm{B}}(\mathrm{xy})=\nu_{\mathrm{A}}(\mathrm{x}) \vee \nu_{\mathrm{A}}(\mathrm{y}) \forall$ $\mathrm{xy} \in \mathrm{E}$. 
Definition: 2.4 Let $\mathrm{G}_{1}:\left(\mathrm{V}_{1}, \mathrm{E}_{1}\right)$ and $\mathrm{G}_{2}:\left(\mathrm{V}_{2}, \mathrm{E}_{2}\right)$ be two IFGs with one or more vertices in common. Then the union of $\mathrm{G}_{1}$ and $\mathrm{G}_{2}$ is another IFG G: $(V, E)=\mathrm{G}_{1} \cup \mathrm{G}_{2}$ defined by,
(i) $\mu_{\mathrm{A}}(\mathrm{x})= \begin{cases}\mu_{1 \mathrm{~A}}(\mathrm{x}) & \forall \mathrm{x} \in \mathrm{V}_{1} \\ \mu_{2 \mathrm{~A}}(\mathrm{x}) & \forall \mathrm{x} \in \mathrm{V}_{2}\end{cases}$
and $\quad v_{\mathrm{A}}(\mathrm{x})= \begin{cases}v_{1 \mathrm{~A}}(\mathrm{x}) & \forall \mathrm{x} \in \mathrm{V}_{1} \\ v_{2 \mathrm{~A}}(\mathrm{x}) & \forall \mathrm{x} \in \mathrm{V}_{2}\end{cases}$
(ii) $\mu_{\mathrm{B}}(\mathrm{xy})= \begin{cases}\mu_{1 \mathrm{~B}}(\mathrm{xy}) & \forall \mathrm{xy} \in \mathrm{E}_{1} \\ \mu_{2 \mathrm{~B}}(\mathrm{xy}) & \forall \mathrm{xy} \in \mathrm{E}_{2}\end{cases}$
and $\quad v_{\mathrm{B}}(\mathrm{xy})= \begin{cases}v_{1 \mathrm{~B}}(\mathrm{xy}) & \forall \mathrm{xy} \in \mathrm{E}_{1} \\ v_{2 \mathrm{~B}}(\mathrm{xy}) & \forall \mathrm{xy} \in \mathrm{E}_{2}\end{cases}$

Definition: 2.5 Let $G_{1}:\left(V_{1}, E_{1}\right)$ and $G_{2}:\left(V_{2}, E_{2}\right)$ be two IFGs with one or more vertices in common. The sum $G_{1}+$ $\mathrm{G}_{2}$ is another IFG $\mathrm{G}:(\mathrm{V}, \mathrm{E})$ defined by,
(i) $\mu_{\mathrm{A}}(\mathrm{x})= \begin{cases}\mu_{1 \mathrm{~A}}(\mathrm{x}) & \forall \mathrm{x} \in \mathrm{V}_{1} \\ \mu_{2 \mathrm{~A}}(\mathrm{x}) & \forall \mathrm{x} \in \mathrm{V}_{2}\end{cases}$ and $\quad v_{\mathrm{A}}(\mathrm{x})= \begin{cases}v_{1 \mathrm{~A}}(\mathrm{x}) & \forall \mathrm{x} \in \mathrm{V}_{1} \\ v_{2 \mathrm{~A}}(\mathrm{x}) & \forall \mathrm{x} \in \mathrm{V}_{2}\end{cases}$
(ii) $\mu_{\mathrm{B}}(\mathrm{xy})= \begin{cases}\mu_{1 \mathrm{~B}} \text { (xy) } & \forall \mathrm{xy} \in \mathrm{E}_{1} \\ \mu_{2 \mathrm{~B}} \text { (xy) } & \forall \mathrm{xy} \in \mathrm{E}_{2}\end{cases}$
and $\quad v_{\mathrm{B}}(\mathrm{xy})= \begin{cases}v_{1 \mathrm{~B}}(\mathrm{xy}) & \forall \mathrm{xy} \in \mathrm{E}_{1} \\ v_{2 \mathrm{~B}}(\mathrm{xy}) & \forall \mathrm{xy} \in \mathrm{E}_{2}\end{cases}$

(iii) There exists a strong edge between every pair of non-common vertices in $G_{1}$ and $G_{2}$

Definition: 2.6 The neighborhood degree of a vertex is defined as $d_{N}(v)=\left(d_{N} \mu(v), d_{N v}(v)\right)$ where $\mathrm{d}_{\mathrm{N} \mu}(\mathrm{v})=\sum_{\mathrm{w} \in \mathrm{N}(\mathrm{v})} \mu_{\mathrm{A}}(\mathrm{w})$ and $\mathrm{d}_{\mathrm{Nv}}(\mathrm{v})=\sum_{\mathrm{w} \in \mathrm{N}(\mathrm{v})} \mathrm{v}_{\mathrm{A}}(\mathrm{w})$.

Definition: 2.7 Let G:(V, E) be an IFG, then the degree of a vertex $v_{i}$ is defined by $\mathrm{d}_{\mathrm{G}}\left(\mathrm{v}_{\mathrm{i}}\right)=\left(\mathrm{d}_{\mu}\left(\mathrm{v}_{\mathrm{i}}\right), \mathrm{d}_{\mathrm{v}}\left(\mathrm{v}_{\mathrm{i}}\right)\right)=\left(\mathrm{k}_{1}, \mathrm{k}_{2}\right)$ where $\mathrm{k}_{1}=\mathrm{d}_{\mu}\left(\mathrm{v}_{\mathrm{i}}\right)=\sum_{\mathrm{v}_{\mathrm{i}} \neq \mathrm{v}_{\mathrm{j}}} \mu_{\mathrm{B}}\left(\mathrm{v}_{\mathrm{i}} \mathrm{v}_{\mathrm{j}}\right)$ and $\mathrm{k}_{2}=\mathrm{d}_{\mathrm{v}}\left(\mathrm{v}_{\mathrm{i}}\right)=\sum_{\mathrm{v}_{\mathrm{i}} \neq \mathrm{v}_{\mathrm{j}}} v_{\mathrm{B}}\left(\mathrm{v}_{\mathrm{i}} \mathrm{v}_{\mathrm{j}}\right)$.

Definition: 2.8 An IFG G:(V, E) is said to be $\left(\mathrm{k}_{1}, \mathrm{k}_{2}\right)$-regular if $\mathrm{d}_{\mathrm{G}}\left(\mathrm{v}_{\mathrm{i}}\right)=\left(\mathrm{k}_{1}, \mathrm{k}_{2}\right)$ for all $\mathrm{v}_{\mathrm{i}} \in \mathrm{V}$ and also $\mathrm{G}$ is said to be a regular IFG of degree $\left(\mathrm{k}_{1}, \mathrm{k}_{2}\right)$.

Definition: 2.9 Let G:(V, E) be an IFG and let $\mathrm{v}_{\mathrm{i}} \mathrm{v}_{\mathrm{j}} \in \mathrm{E}$ be an edge in $\mathrm{G}$, then the degree of $\mathrm{v}_{\mathrm{i}} \mathrm{v}_{\mathrm{j}} \in \mathrm{E}$ is defined by

$$
\begin{aligned}
& \mathrm{d}_{\mu}\left(\mathrm{v}_{\mathrm{i}} \mathrm{v}_{\mathrm{j}}\right)=\mathrm{d}_{\mu}\left(\mathrm{v}_{\mathrm{i}}\right)+\mathrm{d}_{\mu}\left(\mathrm{v}_{\mathrm{j}}\right)-2 \mu_{\mathrm{B}}\left(\mathrm{v}_{\mathrm{i}} \mathrm{v}_{\mathrm{j}}\right) \\
& \sum \sum \\
& =\mathrm{v}_{\mathrm{i}} \mathrm{v}_{\mathrm{k}} \in \mathrm{E}\left[\mu_{\mathrm{B}}\left(\mathrm{v}_{\mathrm{i}} \mathrm{v}_{\mathrm{k}}\right)\right]+\mathrm{v}_{\mathrm{k}} \mathrm{v}_{\mathrm{j}} \in \mathrm{E}\left[\mu_{\mathrm{B}}\left(\mathrm{v}_{\mathrm{k}} \mathrm{v}_{\mathrm{j}}\right)\right] \\
& \mathrm{k} \neq \mathrm{j} \quad \mathrm{k} \neq \mathrm{i} \\
& \mathrm{d}_{v}\left(\mathrm{v}_{\mathrm{i}} \mathrm{v}_{\mathrm{j}}\right)=\mathrm{d}_{v}\left(\mathrm{v}_{\mathrm{i}}\right)+\mathrm{d}_{v}\left(\mathrm{v}_{\mathrm{j}}\right)-2 \mathrm{v}_{\mathrm{B}}\left(\mathrm{v}_{\mathrm{i}} \mathrm{v}_{\mathrm{j}}\right) \quad \text { (or) } \\
& \sum \sum \\
& =\mathrm{v}_{\mathrm{i}} \mathrm{v}_{\mathrm{k}} \in \mathrm{E}\left[\mathrm{v}_{\mathrm{B}}\left(\mathrm{v}_{\mathrm{i}} \mathrm{v}_{\mathrm{k}}\right)\right]+\mathrm{v}_{\mathrm{k}} \mathrm{v}_{\mathrm{j}} \in \mathrm{E}\left[\mathrm{v}_{\mathrm{B}}\left(\mathrm{v}_{\mathrm{k}} \mathrm{v}_{\mathrm{j}}\right)\right] \\
& \mathrm{k} \neq \mathrm{j} \quad \mathrm{k} \neq \mathrm{i}
\end{aligned}
$$

and the edge degree of $G$ is defined by $d_{G}\left(v_{i} v_{j}\right)=\left(d_{\mu}\left(v_{i} v_{j}\right), d_{v}\left(v_{i} v_{j}\right)\right)$.

Definition: 2.10 Let G:(V, E) be an IFG and let $\mathrm{v}_{\mathrm{i}} \mathrm{v}_{\mathrm{j}} \in \mathrm{E}$ be an edge in $\mathrm{G}$, then the total edge degree of $\mathrm{v}_{\mathrm{i}} \mathrm{v}_{\mathrm{j}} \in \mathrm{E}$ is<smiles>[3H]</smiles>

defined by $\operatorname{td}_{\mu}\left(\mathrm{v}_{\mathrm{i}} \mathrm{v}_{\mathrm{j}}\right)=\mathrm{v}_{\mathrm{i}} \mathrm{v}_{\mathrm{k}} \in \mathrm{E}\left[\mu_{\mathrm{B}}\left(\mathrm{v}_{\mathrm{i}} \mathrm{v}_{\mathrm{k}}\right)\right]+\mathrm{v}_{\mathrm{k}} \mathrm{v}_{\mathrm{j}} \in \mathrm{E}\left[\mu_{\mathrm{B}}\left(\mathrm{v}_{\mathrm{k}} \mathrm{v}_{\mathrm{j}}\right)\right]+\mu_{\mathrm{B}}\left(\mathrm{v}_{\mathrm{i}} \mathrm{v}_{\mathrm{j}}\right)$ and

$$
\begin{array}{ccc}
k \neq j & k \neq i & k \\
\operatorname{td}_{v}\left(v_{i} v_{j}\right)=v_{i} v_{k} \in E & E \\
k \neq j & {\left[v_{B}\left(v_{i} v_{k}\right)\right]+v_{k} v_{j} \in E} & k \neq i
\end{array}
$$

and the total edge degree of $\mathrm{G}$ is defined by $\operatorname{td}_{\mathrm{G}}\left(\mathrm{v}_{\mathrm{i}} \mathrm{v}_{\mathrm{j}}\right)=\left(\operatorname{td}_{\mu}\left(\mathrm{v}_{\mathrm{i}} \mathrm{v}_{\mathrm{j}}\right), \operatorname{td}_{\mathrm{v}}\left(\mathrm{v}_{\mathrm{i}} \mathrm{v}_{\mathrm{j}}\right)\right)$.

Definition: 2.11 Let G:(V, E) be an IFG, if each edge in $G$ has the same degree $\left(1_{1}, l_{2}\right)$ then $G$ is said to be an edge regular IFG.

With the above definitions in view, we try to extend the study on regular intuitionistic fuzzy graphs and their properties. Here, in section: 3, we have introduced a new notion on the degree of vertices and degree of edges in intuitionistic fuzzy graphs. Accordingly extended degree of vertices and extended degree of edges have been introduced and on the basis of these, extended vertex regular intuitionistic fuzzy graphs, extended edge regular intuitionistic fuzzy graphs and extended regular intuitionistic fuzzy graphs are also introduced and their properties are studied in the following section. 


\section{Extended Regular Intuitionistic Fuzzy Graph}

Definition: 3.1 Extended vertex degree of a vertex $\mathrm{x} \in \mathrm{V}$ of an IFG G:(V, E) is defined by $\varepsilon \mathrm{d}_{\mathrm{A}}(\mathrm{x})=\left(\varepsilon \mathrm{d}_{\mu}(\mathrm{x}), \varepsilon \mathrm{d}_{v}(\mathrm{x})\right)$ where $\varepsilon \mathrm{d}_{\mu}(\mathrm{x})=\sum_{x \neq y}\left[\mu_{\mathrm{B}}(\mathrm{xy})\right]+\mu_{\mathrm{A}}(\mathrm{x})$ and $\varepsilon \mathrm{d}_{v}(\mathrm{x})=\sum_{x \neq y}\left[v_{\mathrm{B}}(\mathrm{xy})\right]+v_{\mathrm{A}}(\mathrm{x})$.

Definition: 3.2 An IFG in which all the vertices are of equal extended vertex degree is known as extended vertex regular IFG.

Example:

This is an extended vertex regular IFG with extended vertex degree $\mathcal{E} \mathrm{d}_{\mathrm{A}}(\mathrm{x})=(0.6,0.7) \forall \mathrm{x} \in \mathrm{V}$.

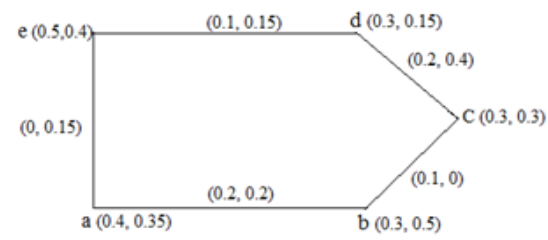

Definition: 3.3 Extended edge degree of an edge $x y \in E$ in an IFG G:(V, E) is defined by

$\varepsilon d_{B}(x y)=\left(\varepsilon d_{\mu}(x y), \varepsilon d_{v}(x y)\right)$ where $\varepsilon d_{\mu}(x y)=\left[\mu_{A}(x)+\mu_{A}(y)\right]-\mu_{B}(x y)$ and

$\varepsilon \mathrm{d}_{\mathrm{v}}(\mathrm{xy})=\left[v_{\mathrm{A}}(\mathrm{x})+v_{\mathrm{A}}(\mathrm{y})\right]-v_{\mathrm{B}}(\mathrm{xy})$

Example:

In this IFG,

$\varepsilon \mathrm{d}_{\mathrm{B}}(\mathrm{ab})=(0.5,0.5), \varepsilon \mathrm{d}_{\mathrm{B}}(\mathrm{bc})=(0.3,0.7)$,

$\varepsilon \mathrm{d}_{\mathrm{B}}(\mathrm{cd})=(0.3,0.1), \varepsilon \mathrm{d}_{\mathrm{B}}(\mathrm{de})=(0.5,0.1)$,

$\varepsilon \mathrm{d}_{\mathrm{B}}(\mathrm{ae})=(0.6,0.5)$

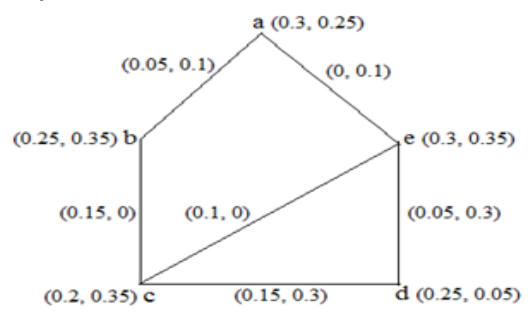

Definition: 3.4 An IFG in which all the edges are of equal extended edge degree is known as extended edge regular IFG.

Example:

This is an extended edge regular IFG with

$\varepsilon \mathrm{d}_{\mathrm{B}}(\mathrm{xy})=(0.6,0.5)$ for all $\mathrm{xy} \in \mathrm{E}$.

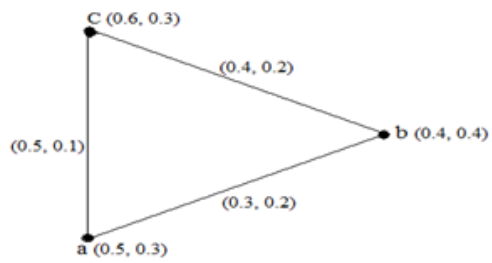

Definition: 3.5 An IFG G:(V, E) is called extended regular IFG if it is both extended vertex regular and extended edge regular.

Example:

This is an extended regular IFG with

$\varepsilon \mathrm{d}_{\mathrm{A}}(\mathrm{x})=(1.0,0.5), \mathcal{E} \mathrm{d}_{\mathrm{B}}(\mathrm{xy})=(0.6,0.3)$

for all $\mathrm{x} \in V$ and $\mathrm{xy} \in \mathrm{E}$.

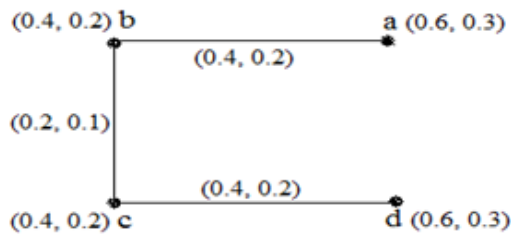

\section{Proposition: 3.6}

In any IFG, G:(V, E) with n vertices $\sum_{\forall x \in V} \varepsilon \mathrm{d}_{\mu}(\mathrm{x})=\sum_{\forall x \in V} \mu_{\mathrm{A}}(\mathrm{x})+2 \sum_{\forall x y \in E} \mu_{\mathrm{B}}(\mathrm{xy})$ and

$\sum_{\forall x \in V} \varepsilon \mathrm{d}_{\mathrm{v}}(\mathrm{x})=\sum_{\forall x \in V} v_{\mathrm{A}}(\mathrm{x})+2 \underset{\forall x y \in E^{v_{\mathrm{B}}(\mathrm{xy})}}{\sum}$

Proof:

We prove the result for an IFG with vertex set $n=2, n=3$ and extend the result for a graph with $n$ vertices by method of induction.

If $\mathrm{n}=1$, where there is only one vertex, the edge set is an empty set as loops does not exist in our study.

If $\mathrm{n}=2$, let $\{\mathrm{V}\}=\left\{\mathrm{v}_{1}, \mathrm{v}_{2}\right\}$ and $\{\mathrm{E}\}=\left\{\mathrm{v}_{1} \mathrm{v}_{2}\right\}$

$$
\begin{aligned}
\sum_{\forall \mathrm{x} \in \mathrm{V}} \varepsilon \mathrm{d}_{\mu}(\mathrm{x}) & =\varepsilon \mathrm{d}_{\mu}\left(\mathrm{v}_{1}\right)+\varepsilon \mathrm{d}_{\mu}\left(\mathrm{v}_{2}\right) \\
& =\mu_{A}\left(\mathrm{v}_{1}\right)+\mu_{B}\left(\mathrm{v}_{1} \mathrm{v}_{2}\right)+\mu_{A}\left(\mathrm{v}_{2}\right)+\mu_{B}\left(\mathrm{v}_{1} \mathrm{v}_{2}\right)=\mu_{A}\left(\mathrm{v}_{1}\right)+\mu_{A}\left(\mathrm{v}_{2}\right)+2 \mu_{B}\left(\mathrm{v}_{1} \mathrm{v}_{2}\right) \\
& =\sum_{\forall \mathrm{x} \in \mathrm{V}} \mu_{\mathrm{A}}(\mathrm{x})+2 \sum_{\forall \mathrm{xy} \in \mathrm{E}} \mu_{\mathrm{B}}(\mathrm{xy})
\end{aligned}
$$

If $\mathrm{n}=3$, let $\{\mathrm{V}\}=\left\{\mathrm{v}_{1}, \mathrm{v}_{2}, \mathrm{v}_{3}\right\}$ and $\{\mathrm{E}\}=\left\{\mathrm{v}_{1} \mathrm{v}_{2}, \mathrm{v}_{2} \mathrm{v}_{3}\right\}$

$\sum_{\forall \mathrm{x} \in \mathrm{V}} \varepsilon \mathrm{d}_{\mu}(\mathrm{x})=\varepsilon \mathrm{d}_{\mu}\left(\mathrm{v}_{1}\right)+\varepsilon \mathrm{d}_{\mu}\left(\mathrm{v}_{2}\right)+\varepsilon \mathrm{d}_{\mu}\left(\mathrm{v}_{3}\right)$

$$
\begin{aligned}
& =\mu_{A}\left(\mathrm{v}_{1}\right)+\mu_{A}\left(\mathrm{v}_{2}\right)+\mu_{A}\left(\mathrm{v}_{3}\right)+2 \mu_{B}\left(\mathrm{v}_{1} \mathrm{v}_{2}\right)+2 \mu_{B}\left(\mathrm{v}_{2} \mathrm{v}_{3}\right) \\
& =\sum_{\forall \mathrm{x} \in \mathrm{V}} \mu_{\mathrm{A}}(\mathrm{x})+2 \sum_{\forall \mathrm{xy} \in \mathrm{E}} \mu_{\mathrm{B}}(\mathrm{xy})
\end{aligned}
$$


For vertex set with $\mathrm{n}-1$ vertices, let $\mathrm{V}=\left\{\mathrm{v}_{1}, \mathrm{v}_{2}, \ldots . \mathrm{v}_{\mathrm{n}-1}\right\}$ and $\mathrm{E}=\left\{\mathrm{v}_{1} \mathrm{v}_{2}, \mathrm{v}_{2} \mathrm{v}_{3}, \ldots . \mathrm{v}_{\mathrm{i}} \mathrm{v}_{\mathrm{j}}\right\} \forall \mathrm{i}, \mathrm{j}=1,2, \ldots \mathrm{n}-1$

$$
\begin{aligned}
& \sum_{\forall \mathrm{x} \in \mathrm{v}} \varepsilon \mathrm{d}_{\mu}(\mathrm{x})=\varepsilon \mathrm{d}_{\mu}\left(\mathrm{v}_{1}\right)+\varepsilon \mathrm{d}_{\mu}\left(\mathrm{v}_{2}\right) \ldots .+\varepsilon \mathrm{d}_{\mu}\left(\mathrm{v}_{\mathrm{n}-1}\right)
\end{aligned}
$$

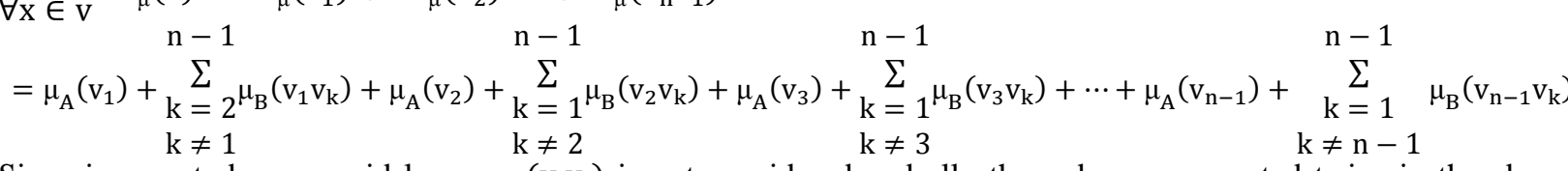

Since in our study we avoid loops $\mu_{\mathrm{B}}\left(\mathrm{v}_{\mathrm{i}} \mathrm{v}_{\mathrm{i}}\right)$ is not considered and all other edges are counted twice in the above equation. (i.e.) $\mu_{\mathrm{B}}\left(\mathrm{v}_{2} \mathrm{v}_{3}\right)$ is same as $\mu_{\mathrm{B}}\left(\mathrm{v}_{3} \mathrm{v}_{2}\right)$.

$\therefore \sum_{\forall \mathrm{x} \in \mathrm{V}} \varepsilon \mathrm{d}_{\mu}(\mathrm{x})=\mu_{\mathrm{A}}\left(\mathrm{v}_{1}\right)+\mu_{\mathrm{A}}\left(\mathrm{v}_{2}\right)+\cdots+\mu_{\mathrm{A}}\left(\mathrm{v}_{\mathrm{n}-1}\right)+2 \sum_{\mathrm{i}, \mathrm{j}=1}^{\mathrm{n}-1} \mu_{\mathrm{B}}\left(\mathrm{v}_{\mathrm{i}} \mathrm{v}_{\mathrm{j}}\right)$
$\therefore \sum_{\forall \mathrm{x} \in \mathrm{V}} \varepsilon \mathrm{d}_{\mu}(\mathrm{x})=\sum_{\forall \mathrm{x} \in \mathrm{V}} \mu_{\mathrm{A}}(\mathrm{x})+2 \sum_{\forall \mathrm{xy} \in \mathrm{E}} \mu_{\mathrm{B}}(\mathrm{xy})$

Hence the result can be extended for vertex set with $\mathrm{n}$ vertices.

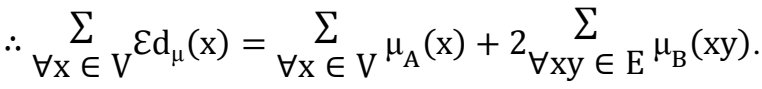

Similarly it can be proved that,

$\sum_{\forall \mathrm{x} \in \mathrm{V}} \mathcal{E} \mathrm{d}_{\mathrm{v}}(\mathrm{x})=\sum_{\forall \mathrm{x} \in \mathrm{V}^{\mathrm{A}}} v_{\mathrm{A}}(\mathrm{x})+2 \sum_{\forall \mathrm{xy} \in \mathrm{E}} v_{\mathrm{B}}(\mathrm{xy})$.

Note: In view that any connected IFG with $n$ edges can have a maximum of $n+1$ vertices, proposition: 3.7 follows.

\section{Proposition: 3.7}

In any IFG, G:(V, E) with $n$ edges

$\sum_{\forall \mathrm{v}_{\mathrm{i}} \mathrm{v}_{\mathrm{j}} \in \mathrm{E}} \varepsilon \mathrm{d}_{\mu}\left(\mathrm{v}_{\mathrm{i}} \mathrm{v}_{\mathrm{j}}\right)=\sum_{\forall \mathrm{v}_{\mathrm{i}} \in \mathrm{V}} \mathrm{k}_{\mathrm{i}}\left(\mu_{\mathrm{A}}\left(\mathrm{v}_{\mathrm{i}}\right)\right)-\underset{\forall \mathrm{v}_{\mathrm{i}} \mathrm{v}_{\mathrm{j}} \in \mathrm{E}}{\sum} \mu_{\mathrm{B}}\left(\mathrm{v}_{\mathrm{i}} \mathrm{v}_{\mathrm{j}}\right)$

$\sum_{\forall \mathrm{v}_{\mathrm{i}} \mathrm{v}_{\mathrm{j}} \in \mathrm{E}} \varepsilon \mathrm{d}_{\mathrm{v}}\left(\mathrm{v}_{\mathrm{i}} \mathrm{v}_{\mathrm{j}}\right)=\sum_{\forall \mathrm{v}_{\mathrm{i}} \in \mathrm{V}} \mathrm{k}_{\mathrm{i}}\left(v_{\mathrm{A}}\left(\mathrm{v}_{\mathrm{i}}\right)\right)-\sum_{\forall \mathrm{v}_{\mathrm{i}} \mathrm{v}_{\mathrm{j}} \in \mathrm{E}} v_{\mathrm{B}}\left(\mathrm{v}_{\mathrm{i}} \mathrm{v}_{\mathrm{j}}\right)$

where $k_{i}$ is number of incident edges to vertex $v_{i}, i, j=1,2 \ldots n+1$ and $i \neq j$.

Proof:

We prove the result for an IFG with edge set $n=1$ and $n=2$ and extend the result for a graph with $n$ edges by method of induction.

If number of edges $\mathrm{n}=1 ;$ Let $\{\mathrm{V}\}=\left\{\mathrm{v}_{1}, \mathrm{v}_{2}\right\}$ and $\{\mathrm{E}\}=\left\{\mathrm{v}_{1} \mathrm{v}_{2}\right\}$

In this case the number of incident edges for both $\mathrm{v}_{1}$ and $\mathrm{v}_{2}$ are $\mathrm{k}_{1}=\mathrm{k}_{2}=1$.

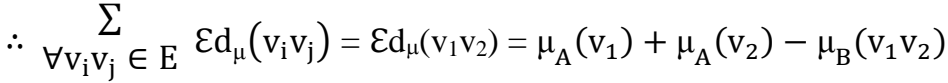

$$
\begin{aligned}
& =\mathrm{k}_{1} \mu_{\mathrm{A}}\left(\mathrm{v}_{1}\right)+\mathrm{k}_{2} \mu_{\mathrm{A}}\left(\mathrm{v}_{2}\right)-\mu_{\mathrm{B}}\left(\mathrm{v}_{1} \mathrm{v}_{2}\right) \\
& \left.\underset{\substack{i=1,2 \\
\forall v_{i} \in V}}{\sum} \sum_{k_{i}} \mu_{A}\left(v_{i}\right)\right]-\underset{\forall v_{i} v_{j} \in E}{ }\left[\mu_{B}\left(v_{i} v_{j}\right)\right]
\end{aligned}
$$

If number of edges, $\mathrm{n}=2$, Let $\{\mathrm{V}\}=\left\{\mathrm{v}_{1}, \mathrm{v}_{2}, \mathrm{v}_{3}\right\}$ and $\{\mathrm{E}\}=\left\{\mathrm{v}_{1} \mathrm{v}_{2}, \mathrm{v}_{2} \mathrm{v}_{3}\right\}$

In this case the number of incident edges to $\mathrm{v}_{1}, \mathrm{v}_{2}$ and $\mathrm{v}_{3}$ are $\mathrm{k}_{1}=\mathrm{k}_{3}=1$ and $\mathrm{k}_{2}=2$.

$$
\begin{aligned}
& \therefore \sum_{\forall \mathrm{v}_{\mathrm{i}} \mathrm{v}_{\mathrm{j}} \in \mathrm{E}} \varepsilon \mathrm{d}_{\mu}\left(\mathrm{v}_{\mathrm{i}} \mathrm{v}_{\mathrm{j}}\right)=\varepsilon \mathrm{d}_{\mu}\left(\mathrm{v}_{1} \mathrm{v}_{2}\right)+\varepsilon \mathrm{d}_{\mu}\left(\mathrm{v}_{2} \mathrm{v}_{3}\right) \\
& =\mu_{\mathrm{A}}\left(\mathrm{v}_{1}\right)+\mu_{\mathrm{A}}\left(\mathrm{v}_{2}\right)-\mu_{\mathrm{B}}\left(\mathrm{v}_{1} \mathrm{v}_{2}\right)+\mu_{\mathrm{A}}\left(\mathrm{v}_{2}\right)+\mu_{\mathrm{A}}\left(\mathrm{v}_{3}\right)-\mu_{\mathrm{B}}\left(\mathrm{v}_{2} \mathrm{v}_{3}\right) \\
& =\mu_{\mathrm{A}}\left(\mathrm{v}_{1}\right)+2 \mu_{\mathrm{A}}\left(\mathrm{v}_{2}\right)+\mu_{\mathrm{A}}\left(\mathrm{v}_{3}\right)-\sum_{\forall \mathrm{v}_{\mathrm{i}} \mathrm{v}_{\mathrm{j}} \in \mathrm{E}} \mu_{\mathrm{B}}\left(\mathrm{v}_{\mathrm{i}} \mathrm{v}_{\mathrm{j}}\right)
\end{aligned}
$$

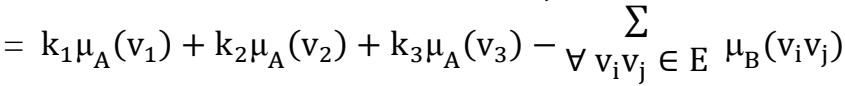

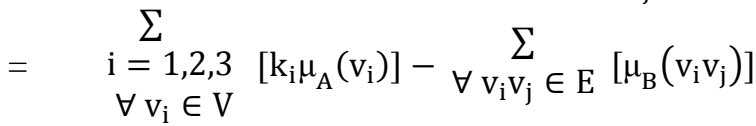

Hence the result can be extended for edge set with $\mathrm{n}$ edges.

$\therefore \underset{\forall v_{i} v_{j} \in E}{\sum} \varepsilon d_{\mu}\left(v_{i} v_{j}\right)=\sum_{\forall v_{i} \in V} k_{i} \mu_{A}\left(v_{i}\right)-\sum_{\forall v_{i} v_{j} \in E} \mu_{B}\left(v_{i} v_{j}\right) ;$ for $i, j=1,2 \ldots \ldots n+1$ and $i \neq j$

Similarly, it can be proved that $\sum_{\forall \mathrm{v}_{\mathrm{i}} \mathrm{v}_{\mathrm{j}} \in \mathrm{E}} \varepsilon \mathrm{d}_{\mathrm{v}}\left(\mathrm{v}_{\mathrm{i}} \mathrm{v}_{\mathrm{j}}\right)=\underset{\forall \mathrm{v}_{\mathrm{i}} \in \mathrm{V}}{\sum} \mathrm{k}_{\mathrm{i}} \mathrm{v}_{\mathrm{A}}\left(\mathrm{v}_{\mathrm{i}}\right)-\sum_{\forall \mathrm{v}_{\mathrm{i}} \mathrm{v}_{\mathrm{j}} \in \mathrm{E}} \mathrm{v}_{\mathrm{B}}\left(\mathrm{v}_{\mathrm{i}} \mathrm{v}_{\mathrm{j}}\right)$. 


\section{Proposition: 3.8}

In an IFG G: $(V, E), \mu_{B}(x y) \leq \varepsilon d_{\mu}(x y)$ and $v_{B}(x y)$ may be greater or less than $\varepsilon d_{v}(x y)$.

Proof:

$\mu_{\mathrm{B}}(\mathrm{xy}) \leq \mu_{\mathrm{A}}(\mathrm{x})$ and $\mu_{\mathrm{B}}(\mathrm{xy}) \leq \mu_{\mathrm{A}}(\mathrm{y})$ from the definition of IFG. Adding the above two statements we get, $2 \mu_{\mathrm{B}}(\mathrm{xy}) \leq \mu_{\mathrm{A}}(\mathrm{x})+\mu_{\mathrm{A}}(\mathrm{y})$.

Subtracting $\mu_{\mathrm{B}}(\mathrm{xy})$ on both sides, $\mu_{\mathrm{B}}(\mathrm{xy}) \leq \mu_{\mathrm{A}}(\mathrm{x})+\mu_{\mathrm{A}}(\mathrm{y})-\mu_{\mathrm{B}}(\mathrm{xy})$

$\therefore \mu_{\mathrm{B}}(\mathrm{xy}) \leq \mathcal{E} \mathrm{d}_{\mu}(\mathrm{xy})$

Since $v_{B}(x y) \leq \max \left(v_{A}(x), v_{A}(y)\right)$ by definition of IFG, $v_{B}(x y)$ may be greater than $v_{A}(x)$ or $v_{A}(y)$.

If $v_{B}(x y)$ is greater than $v_{A}(x)$ and is equal to $v_{A}(y)$, then $v_{A}(x)+v_{A}(y)-v_{B}(x y)<v_{B}(x y)$

where as if $v_{B}(x y)$ is greater than $v_{A}(x)$ and is less to $v_{A}(y)$ then $v_{A}(x)+v_{A}(y)-v_{B}(x y)$ may be greater than or equal to $v_{\mathrm{B}}(\mathrm{xy})$. Hence $\varepsilon d_{\nu}(\mathrm{xy})$ may be greater or less than $v_{\mathrm{B}}(\mathrm{xy})$.

\section{Proposition: 3.9}

If G: $(V, E)$ be an IFG and $\bar{G}:(\bar{V}, \bar{E})$ be its complement then,

$\bar{\mu}_{\mathrm{B}}(\mathrm{xy})+\left[\bar{\mu}_{\mathrm{A}}(\mathrm{x}) \vee \bar{\mu}_{\mathrm{A}}(\mathrm{y})\right]=\varepsilon \mathrm{d}_{\mu}(\mathrm{xy})$ and $\bar{v}_{\mathrm{B}}(\mathrm{xy})+\left[\bar{v}_{\mathrm{A}}(\mathrm{x}) \wedge \bar{v}_{\mathrm{A}}(\mathrm{y})\right]=\varepsilon \mathrm{d}_{v}(\mathrm{xy})$ if $\mathrm{xy} \in \mathrm{E}$.

Proof:

By definition of complement, $\bar{\mu}_{\mathrm{B}}(\mathrm{xy})=\left[\mu_{\mathrm{A}}(\mathrm{x}) \wedge \mu_{\mathrm{A}}(\mathrm{y})\right]-\mu_{\mathrm{B}}(\mathrm{xy})$.

$\therefore \bar{\mu}_{\mathrm{B}}(\mathrm{xy})+\left[\mu_{\mathrm{A}}(\mathrm{x}) \vee \mu_{\mathrm{A}}(\mathrm{y})\right]=\left[\mu_{\mathrm{A}}(\mathrm{x}) \vee \mu_{\mathrm{A}}(\mathrm{y})\right]+\left[\mu_{\mathrm{A}}(\mathrm{x}) \wedge \mu_{\mathrm{A}}(\mathrm{y})\right]-\mu_{\mathrm{B}}(\mathrm{xy})$

$\therefore \bar{\mu}_{\mathrm{B}}(\mathrm{xy})+\left[\bar{\mu}_{\mathrm{A}}(\mathrm{x}) \vee \bar{\mu}_{\mathrm{A}}(\mathrm{y})\right]=\mu_{\mathrm{A}}(\mathrm{x})+\mu_{\mathrm{A}}(\mathrm{y})-\mu_{\mathrm{B}}(\mathrm{xy})=\varepsilon \mathrm{d}_{\mu}(\mathrm{xy})$

Similarly it can be shown that, $\bar{v}_{B}(x y)=\left[\bar{v}_{A}(x) \wedge \bar{v}_{A}(y)\right]=\varepsilon d_{v}(x y)$.

Remark: If $\mathrm{xy} \notin \mathrm{E}$, then $\varepsilon \mathrm{d}_{\mu}(\mathrm{xy})=0$ and $\varepsilon \mathrm{d}_{v}(\mathrm{xy})=0$. Hence by definition of complement IFG, $\bar{\mu}_{\mathrm{B}}(\mathrm{xy})=\left[\mu_{\mathrm{A}}(\mathrm{x}) \wedge \mu_{\mathrm{A}}(\mathrm{y})\right]=\left[\bar{\mu}_{\mathrm{A}}(\mathrm{x}) \wedge \bar{\mu}_{\mathrm{A}}(\mathrm{y})\right]$ and $\bar{v}_{\mathrm{B}}(\mathrm{xy})=\left[v_{\mathrm{A}}(\mathrm{x}) \vee v_{\mathrm{A}}(\mathrm{y})\right]=\left[\bar{v}_{\mathrm{A}}(\mathrm{x}) \vee \bar{v}_{\mathrm{A}}(\mathrm{y})\right]$

\section{Proposition: 3.10}

The necessary condition for a strong IFG to be an extended edge regular IFG is

$\left(\mu_{\mathrm{A}}(\mathrm{x}) \wedge \mu_{\mathrm{A}}(\mathrm{y})\right)=\mathrm{c}_{1}$ and $\left(v_{\mathrm{A}}(\mathrm{x}) \wedge v_{\mathrm{A}}(\mathrm{y})\right)=\mathrm{c}_{2} \forall$ xy $\in \mathrm{E}$ where $\left(\mathrm{c}_{1}, \mathrm{c}_{2}\right)=\mathcal{E} \mathrm{d}_{\mathrm{B}}(\mathrm{xy})$.

Proof:

Let G: $(V, E)$ be a strong IFG. By definition $\mu_{B}(x y)=\left[\mu_{A}(x) \wedge \mu_{A}(y)\right]$ and $v_{B}(x y)=\left[v_{A}(x) \vee v_{A}(y)\right]$ and since $\mu_{\mathrm{A}}(\mathrm{x})+\mu_{\mathrm{A}}(\mathrm{y})-\mu_{\mathrm{B}}(\mathrm{xy})=\varepsilon \mathrm{d}_{\mu}(\mathrm{xy})$,

$\therefore \mu_{\mathrm{A}}(\mathrm{x})+\mu_{\mathrm{A}}(\mathrm{y})-\left[\mu_{\mathrm{A}}(\mathrm{x}) \wedge \mu_{\mathrm{A}}(\mathrm{y})\right]=\varepsilon \mathrm{d}_{\mu}(\mathrm{xy})$

$\Rightarrow\left[\mu_{\mathrm{A}}(\mathrm{x}) \vee \mu_{\mathrm{A}}(\mathrm{y})\right]=\varepsilon \mathrm{d}_{\mu}(\mathrm{xy})$

$\therefore\left[\mu_{\mathrm{A}}(\mathrm{x}) \vee \mu_{\mathrm{A}}(\mathrm{y})\right]=\mathrm{c}_{1} \forall \mathrm{xy} \in \mathrm{E}$.

Similarly it can be shown that $\left[v_{\mathrm{A}}(\mathrm{x}) \wedge v_{\mathrm{A}}(\mathrm{y})\right]=\mathrm{c}_{2} \forall \mathrm{xy} \in \mathrm{E}$.

$\therefore\left[\mu_{\mathrm{A}}(\mathrm{x}) \vee \mu_{\mathrm{A}}(\mathrm{y})\right]=\mathrm{c}_{1}$ and $\left[v_{\mathrm{A}}(\mathrm{x}) \wedge v_{\mathrm{A}}(\mathrm{y})\right]=\mathrm{c}_{2}$ where $\left(\mathrm{c}_{1}, \mathrm{c}_{2}\right)=\varepsilon \mathrm{d}_{\mathrm{B}}(\mathrm{xy}) \forall \mathrm{xy} \in \mathrm{E}$.

\section{Proposition: 3.11}

A strong IFG which is extended edge regular is extended vertex regular IFG if all the vertices and edges have the same membership and non-membership values, and hence it must be extended regular IFG.

Proof:

By definition of strong IFG and by above Proposition: 6, all the incident edges $\mu_{\mathrm{B}}(\mathrm{xy})=\mu_{\mathrm{A}}(\mathrm{x}) \wedge \mu_{\mathrm{A}}(\mathrm{y})$ and hence $\varepsilon d_{A}(x)$ and $\varepsilon d_{A}(y)$ will be equal only if $\mu_{A}(x)$ and $\mu_{A}(y)$ are all equal for every $x \in V$ since $\varepsilon d_{B}(x y)=\left(c_{1}, c_{2}\right)$ is constant for all the edges. Hence minimum and maximum of both the end vertices of all edges must be equal in an extended edge regular IFG, which is again equal to $\mu_{\mathrm{B}}(\mathrm{xy}) . \therefore \varepsilon \mathrm{d}_{\mathrm{A}}(\mathrm{x})=\left(\mathrm{c}_{1}, \mathrm{c}_{2}\right) \forall \mathrm{x} \in \mathrm{V}$.

$\therefore$ Combining both the results $\mathcal{E} \mathrm{d}_{\mathrm{B}}(\mathrm{xy})=\left(\mathrm{c}_{1}, \mathrm{c}_{2}\right) \forall \mathrm{xy} \in \mathrm{E}$ and $\mathcal{E} \mathrm{d}_{\mathrm{A}}(\mathrm{x})=\left(\mathrm{c}_{1}, \mathrm{c}_{2}\right) \forall \mathrm{x} \in \mathrm{V}$ gives, all the vertices and edges have equal membership and non-membership values. Hence it is an extended regular IFG.

Proposition: 3.12

A Hamiltonian IFG G: (V, E) with $\mathrm{n}$ vertices and $\mathrm{n}$ edges which is extended regular IFG satisfies the following conditions.

i. $\quad\left(\mu_{\mathrm{A}}(\mathrm{x}), v_{\mathrm{A}}(\mathrm{x})\right)=\left(\mathrm{c}_{1}, \mathrm{c}_{2}\right) \forall \mathrm{x} \in \mathrm{V}$.

ii. $\quad\left(\mu_{\mathrm{B}}(\mathrm{xy}), v_{\mathrm{B}}(\mathrm{xy})\right)=\left(\mathrm{c}_{3}, \mathrm{c}_{4}\right) \forall \mathrm{xy} \in \mathrm{E}$.

Proof:

i. Let a Hamiltonian IFG G: (V, E) be extended regular IFG. Let $\{\mathrm{V}\}=\left\{\mathrm{v}_{1}, \mathrm{v}_{2}, \ldots \ldots \mathrm{v}_{\mathrm{n}}\right)$ and $\mathrm{E}=\left\{\mathrm{v}_{1} \mathrm{v}_{2}, \mathrm{v}_{2} \mathrm{v}_{3}, \ldots, \mathrm{v}_{\mathrm{n}-1} \mathrm{v}_{\mathrm{n}}, \mathrm{v}_{\mathrm{n}} \mathrm{v}_{1}\right\}$ 
Since $\mathrm{G}$ is extended regular IFG, the extended vertex degrees of all vertices are equal.

$\therefore \varepsilon \mathrm{d}_{\mu}\left(\mathrm{v}_{1}\right)=\varepsilon \mathrm{d}_{\mu}\left(\mathrm{v}_{2}\right)=\ldots=\varepsilon \mathrm{d}_{\mu}\left(\mathrm{v}_{\mathrm{n}-1}\right)=\varepsilon \mathrm{d}_{\mu}\left(\mathrm{v}_{\mathrm{n}}\right)$

$\mu_{\mathrm{B}}\left(\mathrm{v}_{\mathrm{n}} \mathrm{v}_{1}\right)+\mu_{\mathrm{B}}\left(\mathrm{v}_{1} \mathrm{v}_{2}\right)+\mu_{\mathrm{A}}\left(\mathrm{v}_{1}\right)=\mu_{\mathrm{B}}\left(\mathrm{v}_{1} \mathrm{v}_{2}\right)+\mu_{\mathrm{B}}\left(\mathrm{v}_{2} \mathrm{v}_{3}\right)+\mu_{\mathrm{A}}\left(\mathrm{v}_{2}\right)=\ldots=\mu_{\mathrm{B}}\left(\mathrm{v}_{\mathrm{n}-2} \mathrm{v}_{\mathrm{n}-1}\right)+\mu_{\mathrm{B}}\left(\mathrm{v}_{\mathrm{n}-1} \mathrm{v}_{\mathrm{n}}\right)+\mu_{\mathrm{A}}\left(\mathrm{v}_{\mathrm{n}-1}\right)=$

Cancelling common terms in above equality,

$$
\mu_{\mathrm{B}}\left(\mathrm{v}_{\mathrm{n}-1} \mathrm{v}_{\mathrm{n}}\right)+\mu_{\mathrm{B}}\left(\mathrm{v}_{\mathrm{n}} \mathrm{v}_{1}\right)+\mu_{\mathrm{A}}\left(\mathrm{v}_{\mathrm{n}}\right)
$$

$\mu_{\mathrm{A}}\left(\mathrm{v}_{1}\right)=\mu_{\mathrm{A}}\left(\mathrm{v}_{2}\right)=\ldots . .=\mu_{\mathrm{A}}\left(\mathrm{v}_{\mathrm{n}}\right)$

$\therefore \quad \mu_{\mathrm{A}}(\mathrm{x})=\mathrm{c}_{1} \forall \mathrm{x} \in \mathrm{V}$. Similarly it can be shown that $v_{\mathrm{A}}(\mathrm{x})=\mathrm{c}_{2} \forall \mathrm{x} \in \mathrm{V}$.

ii. $\quad$ Since $\mathrm{G}$ is extended regular IFG, the extended edge degree of all edges are equal.

$\therefore \varepsilon \mathrm{d}_{\mu}\left(\mathrm{v}_{1} \mathrm{v}_{2}\right)=\varepsilon \mathrm{d}_{\mu}\left(\mathrm{v}_{2} \mathrm{v}_{3}\right)$.

$\mu_{\mathrm{A}}\left(\mathrm{v}_{1}\right)+\mu_{\mathrm{A}}\left(\mathrm{v}_{2}\right)-\mu_{\mathrm{B}}\left(\mathrm{v}_{1} \mathrm{v}_{2}\right)=\mu_{\mathrm{A}}\left(\mathrm{v}_{2}\right)+\mu_{\mathrm{A}}\left(\mathrm{v}_{3}\right)-\mu_{\mathrm{B}}\left(\mathrm{v}_{2} \mathrm{v}_{3}\right)$

By (i), $\mu_{\mathrm{A}}\left(\mathrm{v}_{\mathrm{i}}\right)=\mathrm{c}_{1} \forall \mathrm{v}_{\mathrm{i}} \in \mathrm{V} . \Rightarrow \mu_{\mathrm{B}}\left(\mathrm{v}_{1} \mathrm{v}_{2}\right)=\mu_{\mathrm{B}}\left(\mathrm{v}_{2} \mathrm{v}_{3}\right)$.

Hence it can be shown that $\mu_{\mathrm{B}}\left(\mathrm{v}_{1} \mathrm{v}_{2}\right)=\mu_{\mathrm{B}}\left(\mathrm{v}_{2} \mathrm{v}_{3}\right)=\ldots \ldots . .=\mu_{\mathrm{B}}\left(\mathrm{v}_{\mathrm{n}-1} \mathrm{v}_{\mathrm{n}}\right)=\mu_{\mathrm{B}}\left(\mathrm{v}_{\mathrm{n}} \mathrm{v}_{1}\right)$

$\therefore \mu_{\mathrm{B}}(\mathrm{xy})=\mathrm{c}_{3} \forall \mathrm{xy} \in \mathrm{E}$. Similarly it can be shown that $\nu_{\mathrm{B}}(\mathrm{xy})=\mathrm{c}_{4} \forall \mathrm{xy} \in \mathrm{E}$.

Note: By the above proposition, in any extended regular IFG, every path is firm path and all arcs are sturdy arcs as defined by the authors in [7].

\section{Extended Regular IFG In Stemcell Therapy - An Analysis}

A report on "Stemcells: 10 Diseases they may- or may not- cure", by "health.usnews.com" released recently can be taken for our study on application of extended regular IFG. According to the report the following are a few of the conditions that can be treated with stemcell therapy that might someday cure - or atleast help treat.

i. Spinal cord Injury: The first - ever human study of a medical treatment derived from human embryonic stemcell helped to regain some feeling in and control over their lower extremities of the spinal cord for a paralyzed volunteer.

ii. Diabetes: Stemcells may be the answer for diabetic patients, whose insulin - making pancreatic cells have been killed off by their immune system.

iii. Arthritis: A degenerative joint disease has been examined by scientists, how best to use them to rebuild and replace shot joints.

iv. Heart disease: Researchers have reported success in injecting the cells into the heart. They could help regenerate heart muscle damage for example, a heart attack.

v. Lung disease: From human embryonic stemcells, researchers in Texas showed lung cells could potentially be used to repair damage brought on by variety of pulmonary conditions.

vi. Organ Failure: Scientists think that with stemcells the vision to grow new organs which is the better way to ease the shortage of new organs may become true more than a mere pipe dream.

Based on this report and data provided, extended edge/vertex regular IFG's are generated for our study. The degree of membership/non-membership of all the vertices and edges are rate of possibility for the disease may / may not be cured with stemcell treatment. The vertices labeled SI, D, A, HD, LD, and OF denote the above six categories of diseases respectively. The degree of membership/non-membership are assigned to all vertices and edges so that it forms corresponding edge regular and vertex regular IFG.
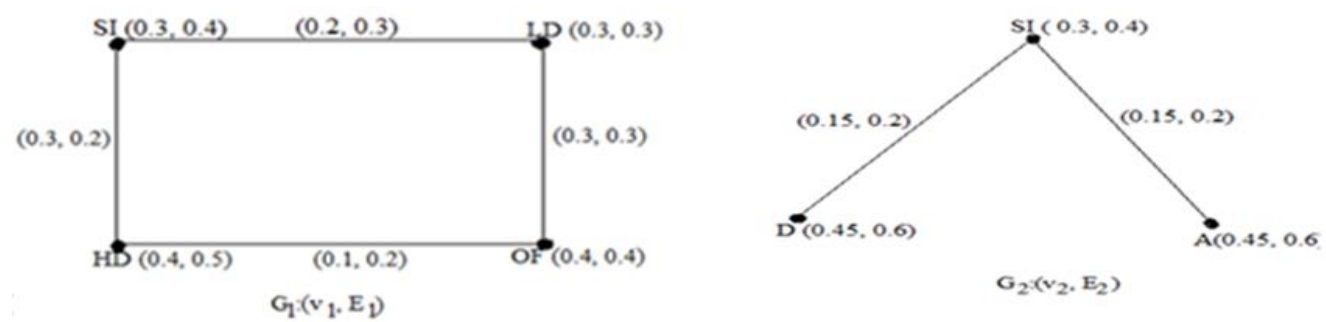

The graphs $\mathrm{G}_{1}:\left(\mathrm{V}_{1}, \mathrm{E}_{1}\right)$ and $\mathrm{G}_{2}:\left(\mathrm{V}_{2}, \mathrm{E}_{2}\right)$ are extended vertex regular IFG and extended edge regular IFG respectively. In particular $\mathrm{G}_{2}:\left(\mathrm{V}_{2}, \mathrm{E}_{2}\right)$ is extended regular IFG in which both $\varepsilon \mathrm{d}_{\mathrm{A}}(\mathrm{x})=\varepsilon \mathrm{d}_{\mathrm{B}}(\mathrm{xy})=(0.6,0.8)$. This can also be called an extended regular IF tree. In both $\mathrm{G}_{1}$ : $\left(\mathrm{V}_{1}, \mathrm{E}_{1}\right)$ and $\mathrm{G}_{2}$ : $\left(\mathrm{V}_{2}, \mathrm{E}_{2}\right)$ the vertex "SI" is common. Hence by definition of operation ' $\cup$ ' as in [6], $G_{1} \cup G_{2}$ is not an extended edge regular IFG. On the other hand if $\mathrm{G}_{\mathrm{i}}$ is extended edge regular IFG and $\mathrm{G}_{\mathrm{j}}$ is extended regular IFG with one or more vertices in common, then $G_{i} \cup G_{j}$ must be extended edge regular IFG. The graph $G_{1} \cup G_{2}$ of the above graphs $\mathrm{G}_{1}:\left(\mathrm{V}_{1}, \mathrm{E}_{1}\right)$ and $\mathrm{G}_{2}:\left(\mathrm{V}_{2}, \mathrm{E}_{2}\right)$ is as follows.

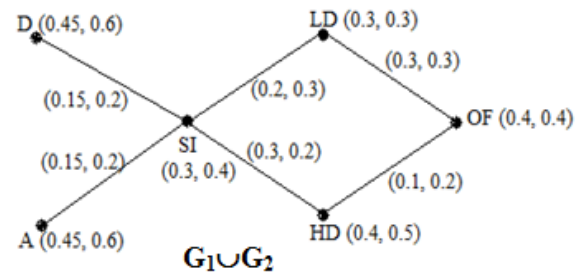


In our above study we have used extended regular IFG to represent the stemcell treatment similar to a graphical method of representing data as we do in histogram or frequency polygon etc. Further it can be used to study the operations such as complement, union, addition etc. The study on arcs of extended edge/vertex regular IFG is also an open problem.

\section{Conclusion}

This study gives a clear idea on degree of an edge in IFG's and new extended degree of edges in IFG's which is more effective in application oriented view. An application to construct an extended regular IFG as a symbolic model to make computation easier is given. The work can be proposed to extend with study on each arc in extended regular IFG. Also extended regular intuitionistic trees, spanning trees etc can be generated which find more areas of application.

\section{References}

[1]. $\quad$ Anthony Shannon and Atanassov, K. "On a generalization of intuitionistic fuzzy graphs." NIFS Vol.12.(1) (2006): 24-29.

[2]. Atanassov, K T. "Intuitionistic fuzzy sets: theory and applications, Studies in Fuzziness and soft computing." Physica-Verlag. Heidelberg, New York, 1999.

[3]. Karunambigai, M G., Palanivel, K., and Sivasankar, S. "Edge regular Intuitionistic fuzzy graphs." Advances in fuzzy sets and systems Vol.20.(1) (2015): 25-46.

[4]. Karunambigai, M G., Sivasankar, S. and Palanivel, K. "Some properties of a regular Intuitionistic fuzzy graphs." International journal of mathematics and computation Vol.26.(4) (2015): 53-61.

[5]. Nagoor Gani, A and Shajitha Begum, S. "Degree, order and size in Intuitionistic fuzzy graphs." International journal of algorithms, computing and mathematics Vol.3.(3) (2010): 11-16.

[6]. Nivethana, V. and Parvathi, A. "On complement of Intuitionistic fuzzy graphs." International journal of computational and applied mathematics Vol.10.(1) (2015): 17-26.

[7]. Nivethana, V. and Parvathi, A. "Arc analysis in the Intuitionistic fuzzy graph and its applications." NIFS Vol.22.(1) (2016): 53-62.

[8]. Parvathi, R., Karunambigai, M G. and Atanassov, K T. "Operations on Intuitionistic fuzzy graphs." Fuzz-IEEE (2009): 20-24.

[9]. Radha, K. and Kumaravel, N. "On edge regular fuzzy graphs." International journal of mathematical archive Vol.5.(9) (2014): 100-112. 